\title{
The Authority of the Fallacies Approach to Argument Evaluation
}

\section{Catherine E. Hundleby}

Department of Philosophy

University of Windsor

Windsor, Ontario

Canada N9B 3P4

Email: hundleby@uwindsor.ca

\begin{abstract}
Popular textbook treatments of the fallacies approach to argument evaluation employ the Adversary Method identified by Janice Moulton (1983) that takes the goal of argumentation to be the defeat of other arguments and that narrows the terms of discourse in order to facilitate such defeat. My analysis of the textbooks shows that the Adversary Method operates as a Kuhnian paradigm in philosophy, and demonstrates that the popular fallacies pedagogy is authoritarian in being unresponsive to the scholarly developments in informal logic and argumentation theory. A progressive evolution for the fallacies approach is offered as an authoritative alternative.
\end{abstract}

Resumé: L'approche employée pour évaluer des arguments qui repose sur l'identification de sophismes qu'on trouve dans les manuels populaires est une Méthode de l'Adversaire, identifiée par Janice Moulton (1983). Le but de cette méthode est de vaincre les arguments des autres et de borner les termes d'un discours pour faciliter leurs défaites. Mon analyse des manuels démontre que la Méthode de l'Adversaire agit comme un paradigme Kuhn en philosophie, et que la pédagogie populaire des sophismes est autoritaire puisqu'elle n'applique pas les résultats des progrès académiques de la logique non formelle et de la théorie d'argumentation. On offre une évolution progressive de l'approche des sophismes comme une alternative légitime.

Key words: adversary, argument, authority, epistemology, fallacy, feminism, pedagogy, paradigm, silence, textbook

\section{Introduction}

I have found the study of fallacies to be fun since I was a student. Students enjoy the quick empowerment that fallacy labels provide, which in turn gives teachers fairly immediate satisfaction for their efforts to engage them. However, the longer I teach about fallacies the more I recognize the multiple murky aspects of what had seemed to be distinct and categorical errors. Fallacies overlap, arguments are ambiguously fallacious, and the schemes of reasoning identified by fallacy labels are perfectly acceptable in many cir-

(C) Catherine E. Hundleby. Informal Logic, Vol. 30, No. 3 (2010), pp. 279-308. 
cumstances. Thus I came to question my pedagogical satisfaction: Are the fallacies arbitrary prohibitions based on empty tradition? What authority does the fallacies approach to argument evaluation have?

My situation was typical of the circumstance that many critical thinking instructors are in, having little or no training in informal logic and argumentation theory, ${ }^{1}$ and resulting in teaching strategies that tend to be out of touch with relevant scholarship. This situation leads instructors to rely on the traditional Adversary Method in teaching fallacies. This highly constrained method, has, as Janice Moulton (1983) describes, operated as a Kuhnian paradigm in the discipline of philosophy. Functioning as a paradigm means deeming to be philosophically irrelevant other approaches to reasoning, both creating epistemological and political problems for the discipline of philosophy, and distorting the fallacies approach to argument evaluation.

I argue in this paper that the popular pedagogy of fallacies involves a corrupt epistemic authority that makes the common practices of fallacy allegation authoritarian. The oppositional nature of fallacy allegation - as when we oppose the arguments that politicians provide by charging them with being fallacious-lends itself to formulation according to the politically regressive and epistemologically archaic Adversary Paradigm. The continuing power of the Adversary Paradigm in philosophy, evidenced by the popular formulation of the fallacies approach in textbooks, and the rigor of philosophical analysis that narrow discourse affords shows its inherent tenaciousness. The Method does not seem to deserve epistemological status as a paradigm, however. Alternative philosophical methodologies are already available (Moulton 1983, p. 154), and many different characterizations of argumentation feel equally natural (Rooney 2004, p. 5; Cohen 1995). Used paradigmatically, the Method seems mostly to serve to alienate and exclude impor-

\footnotetext{
${ }^{1}$ In the United States more than $60 \%$ of faculty positions are now contingentnot tenure-track (S. Jaschik, The disappearing tenure-track job, Inside Higher Ed, May 12, 2009 http://www.insidehighered.com/news/2009/05/12/workforce). Given that informal logic (or argumentation theory) lacks status as an "Area of Specialization" or even "Area of Competency" named with any regularity in Jobs for Philosophers, most job-candidates have no long-term motivation to pursue scholarship that would support their critical thinking instruction. Also, argumentation has low status within philosophy and philosophers are generally disinterested in methodology. Therefore, studying argumentation does not contribute to the status and research goals of permanent faculty who will, as a result, when they can, opt not to teach critical thinking. I have located no formal study of the preparation of critical thinking instructors. However, at readings of this paper at philosophy conferences not directly concerning argumentation-with a selfselected audience-I found that only $50 \%$ of the audience members who had taught critical thinking had ever read a scholarly paper in informal logic or argumentation theory.
} 
tant forms of reasoning. Popular fallacies pedagogy deviates dramatically from textbooks by current scholars in argumentation and informal logic. Not only is Moulton's view that the Adversary Method has the force of a paradigm in philosophy supported by what I show below, but also the Method's near-casual but consistent acceptance raises questions about the epistemic authority of the popular presentation of fallacies as a means of argument evaluation.

To explore the problematic authority of the popular fallacies approach, I begin by explaining what I mean by "the fallacies approach to argument evaluation" using Douglas Walton's account (1995) as a scholarly foundation. I will then explain the Adversary Method independent of its paradigmatic status, and proceed to show by analyzing thirty textbooks that the Adversary Method dominates textbook treatments of the fallacies approach through a series of conventional practices. These practices include attitudes toward argument repair, insubstantial examples, and highly stylized, as well as carefully constrained, exercises. Although there are exceptions to the formats I point out in the textbooks, my analysis reveals a strong overarching pattern that has both liberatory pedagogical and epistemological implications.

In the course of this discussion, I question the discursive impact of the Adversary Method as a paradigm of philosophical reasoning and of argumentation more generally, and examine the political implications of the Paradigm's operation in critical thinking instruction. Updating the fallacies approach to argument evaluation will rectify its epistemic authority. It can also create greater personal and social relevance for philosophy and critical thinking especially when we extend our considerations to address and name the errors of reasoning that perpetuate injustice (Hundleby, 2010).

\section{The fallacies approach to argument evaluation: scholarship and pedagogy}

By "the fallacies approach to argument evaluation" I generally mean the typologies of mistakes that reasoners use to scrutinize the quality of an argument, typologies that both scholarly and textbook accounts list. There are many different lists, and not every error in argumentation is baptized as a fallacy and given a title. A standard set described by John Woods as "the gang of eighteen" (2004, p. 45), mostly derived from Aristotle, includes such fallacies as "begging the question" and "equivocation." 2 The names usually emerge

\footnotetext{
${ }^{2}$ Woods' list is not meant to be exhaustive and includes ad baculum (appeal to force), ad misericordiam (appeal to pity), ad populum (appeal to popular opinion), ad verecundiam (appeal to authority), ad hominem (appeal to the person),
} 
from the histories of philosophy, logic, and rhetoric, and have become quite familiar in introductory instruction in logic and critical thinking during the twentieth century.

On the scholarly side, to provide contrast with the textbook presentation, I follow Walton's (1995, p. 15-18) definition of a fallacy as a serious misuse of an argument scheme. Argument schemes are presumptive forms of reasoning that go awry when the burden of proof is not fulfilled, leaving the presumption without the necessary qualification. Presumptive reasoning employs generalizations that admit of exceptions (Walton 2006a, p. 3) - so, it can be cogent or fallacious. The schemes of presumptive reasoning, such as appeals to emotion, to popular opinion, and to personal qualities, provide good reasoning in many standard cases, or at least in certain circumstances (Walton 2006a, Tindale 2007a). Consider for instance that emotional appeals, which can be fallacious, also can be crucial to catch the interest of one's audience and demonstrate the significance of one's claims. In discussions regarding morality or safety, appeals to pity or fear are not always fallacious, and may assist in presenting the full strength of reasoning. Only when the burden of proof is not fulfilled is the presumptive move in dialogue illegitimate, and a fallacy committed.

There are several reasons why I take Walton's account as my point of departure. First, it is the most developed approach to fallacies of argumentation, evolving over decades in response to scholarship, and unmatched in depth and breadth. Harking back to Aristotle, and building on pragma-dialectics by attending to discourse, ${ }^{3}$ Walton's approach addresses a variety of discursive forms. Recognizing discourse, to begin with, as well as its multiple forms more fully represents the processes of argumentation than do the abstract premise-conclusion complexes that have been common subject matter in United States' and Canadian textbooks.

Textbook presentations bear the brunt of my criticism and are the focus of my concern because of their epistemological influence on the thinking and beliefs of people in the larger society. The conditions for the production of epistemological theorizing and the content of its background assumptions have broad political effects, as Linda Alcoff (1983) argues. Because of this social significance,

affirming the consequent, denying the antecedent, amphiboly (word order providing two meanings), biased statistics, complex question, composition and division, faulty analogy, hasty generalization, secundum quid (neglecting exceptions), gambler's fallacy, and ignoratio elenchi (generally an irrelevant appeal or, if acutely distracting, "red herring").

3 The "Amsterdam school" of pragma-dialectics, originated by Frans van Eemeren and Rob Grootendorst, evaluates argumentation relative to an ideal of using critical discourse to resolve differences of opinion. For a helpful account see chapter 10, "Pragma-dialectics and critical discussion, in van Eemeren, Grootendorst, Snoeck Henkemans, et al. (1996). 
epistemology can legitimate certain discourses and de-legitimate others:

Philosophy is not just one discourse among many discourses of knowledge; it is, rather, the discourse that sets out the structures of legitimation for all other discourses. This is particularly true of epistemology, which takes as its objective the delineation of a conceptual apparatus by which all knowledge claims can be judged. (p. 72)

I maintain that the pedagogy of argumentation has an even greater impact on the legitimation of discourses, and on the authorization of particular voices, structures, and styles of reasoning than the theories of knowledge students may learn in an epistemology class. Critical thinking courses that teach argument evaluation are a basic component of liberal arts and legal education, providing the only logic and epistemology training-even the only philosophy education - that most students in the global North receive. ${ }^{4}$ Critical thinking training is, in general, where the rubber of epistemology hits the road of epistemic and philosophical practice in the larger society. Typically, critical thinking courses include a week or two on fallacies, and legal education programs devote a day or so. Among techniques of argument evaluation, the heuristic nature of fallacy labels makes them handy, convenient, and memorable — altogether highly useful. In addition, the classical pedigree of fallacies heightens students' discursive credibility in many contexts, allowing them to show off their education by dropping a little Latin into conversation. Thus, philosophical epistemology transmitted through critical thinking instruction gains an authority that requires closer examination.

In Walton's account, fallacy allegation shifts dialogue to consider the available advice, via the questions surrounding a particular type of presumption (1997, p. 121-23). This means the burden of proof is ambiguous once a fallacy has been alleged: it remains either for the critic or the arguer to address the critical questions. ${ }^{5}$ In principle, one opens up discourse when alleging that an argument commits a fallacy. Alleging that a fallacy has been committed

\footnotetext{
${ }^{4}$ My speaking generally of the global admittedly obscures differences among cultures and subcultures, but my aim is to recognize broad commonalities regarding the articulation of gender in many of the specific contexts.

${ }_{5}^{5}$ In another place Walton claims that to allege a fallacy has been committed is to shift the burden of proof back to the arguer, which reinforces the original burden of proof $(1995$, p. 5, 18). Such reinforcement often may be the effect of a fallacy allegation but only if the alleger has greater social status than the arguer, I suggest. Some of that status may be conveyed by the use of the fallacies approach itself (see section 6), which is part of the reason I am concerned about its authority.
} 
interrupts discourse in a way that Cheryl Glenn (2004) describes as a rhetorical silence: it interrupts or stops the line of reasoning offered by pausing or shifting the dialogue, and it appears to be full of meaning while remaining ambiguous. The ambiguity derives from whether or not the burden of proof is on the alleger to demonstrate that a fallacy was committed or on the arguer to defend the argument. The person who alleges that a fallacy was committed refuses to continue the discussion without stopping to address questions related to that fallacy. For instance, if I allege that Alice begged the question, I ask her to show me that her premises are independent from her conclusion, or I indicate that I can show her how her premise seems to assume the truth of her conclusion. In either case, I raise questions regarding her burden of proof, opposing it minimally. That questioning need not involve my forcing Alice into artificial terms of debate with the goal of defeating her position (though sometimes fallacy allegation does exactly that). The silence can be disambiguated, but that typically is through interpretation by the person holding the greater social status.

My criticism of popular versions of the fallacies approach is based on Moulton's (1983) critique of the Adversary Method as a paradigm of reasoning in philosophy. With Moulton I recognize that the style of reasoning she dubs the Adversary Method is useful for a certain situation: namely when the disagreements are isolated (p. 154), the problems are between opponents (p. 157), and further we need to rule out options. Also with her I deny that it is the most effective or useful form of reasoning, and deny that it deserves to operate as a Kuhnian paradigm in philosophy.

\section{The Adversary Method}

The Adversary Method evaluates an argument by subjecting it "to the strongest or most extreme opposition" (Moulton 1983, p. 153), in an attempt to get the best of both sides of a dispute. ${ }^{6}$ The Method considers two contrasting views beginning with what we may call an "oppositional" position, a contrary view on a particular topic, and assumes the goal of defeating another's view. It provides objective support to the view that survives, and that continues to survive such opposition. Objectivity derives from the "uniform severity" of opposition, regardless of the content of the view being considered.

\footnotetext{
${ }^{6}$ Moulton speaks as if there were only two sides to a given dispute. While a dispute may have more sides, the narrowing of debate by the Adversary Method tends to narrow the room for opposition; thus, a binary will be most common. Because a binary also allows one side to clearly win, it will be the ideal format for employing the Adversary Method.
} 
The oppositional project is facilitated, Moulton claims, by the distortion of people's positions and concerns through narrowing of the topic, or target, which also distinctly limits the practical applications of the Method. The Method works best when applied to isolated disagreements and particular claims. It often proceeds by raising objections through counterexample, or by granting premises for the sake of argument. Thus, we "withhold evaluation for a system of ideas in order to find common ground for debate" (1983, p. 155). As philosophers we typically fight our opponents on their terms to the extent that we can. So, for example, we engage questions about knowledge as epistemologists and not as ethicists, defining ourselves as foundationalist, coherentist, or realist; internalist or externalist; and pragmatist or idealist. ${ }^{7}$ While these categories seem to provide clarity, they can distort the position under consideration by pressing it into a context of consideration different from the one in which it originates. So, for instance, we find moral theories addressed to egoists, theories of knowledge aimed at skeptics, Moulton decries. "We find an abundance of accounts trying to prove that determinism is false because free will exists..."8 (Moulton, 1983, p. 158).

Forced distinctions artificially slow the development of thought, which comes to rely on ad hoc revisions instead of systematic reconsiderations that would allow theories to evolve. Philosophers revive and debate old arguments about whether God exists, but leave all current discussions about what the nature of God would be to divinity schools and religious orders. (Moulton, 1983, p. 158) Exceptional "programmatic" views are allowed, Moulton suggests, only because or insofar as they refuse at all to address counterexamples $(1983$, p. 155$){ }^{9}$

While recognizing the important purposes that philosophical reasoning and argumentation can serve, Moulton illustrates the inadequacy of the Adversary Method by considering Judith Jarvis Thomson's defense of abortion (1971). Thomson employs the Adversary Method in arguing that even if one accepts that the fetus a person, that is not sufficient to make abortion wrong. The personhood of the fetus is granted for the sake of argument, a move common for the Adversary Method because it limits the scope of discourse. Thomson's argument is a fine example of the Adversary

\footnotetext{
${ }^{7}$ I borrow this epistemological illustration from Lorraine Code (1995, p. 12).

${ }^{8}$ In the ellipsis, Moulton writes that there are "no positive accounts giving an explanation, in terms of chance and indeterminism, of what free will would be." Her criticism may have been accurate at the time, but philosophy of mind involves more positive accounts of freedom now, often involving physics and biology.

9 A Popperian appeal to deductive refutation supports the Adversary Method, according to Moulton (1983, p. 152-3), and part of her concern is the inadequacy of deductivism, but I will not take that up here.
} 
Method because it shows that the personhood of the fetus is not more important morally than a woman's right to decisions about her body - the right to life does not outweigh the right to control one's own body. However, Thomson's abstract reasoning provides no guidance about when it is morally acceptable to have an abortion, or should one want to reason about whether to have an abortion (1983, p. 159-60). Complex practical questions do not fair well with the Adversary Method, which only examines select narrow alternatives, to rule some out. In order to facilitate the ruling out, the Method abstracts positions from the contexts that give them practical significance. As the discipline that develops and assesses ideals of reasoning and behavior, philosophy can and should serve us better.

\section{The textbook treatments of fallacies}

Using fallacy categories as a means of argument evaluation means learning how to allege that a fallacy has been committed. While fallacy allegation need not involve the Adversary Method, it almost always does in the textbooks. The problems arise out of the presentation of arguments. The consideration of argument repair would suggest uses and functions of argumentation beyond defeating opposing positions, but that possibility is usually neglected. Examples are often skewed, consisting of the more than $50 \%$ use of short examples of a few sentences, removing the premise and conclusion from the dialectical context in which they occur, and increasing an argument's vulnerability to criticism. Likewise examples manufactured by the textbook author eliminate further contextual elements that can lend credibility to a competing argument-again, when it reaches a rate of $50 \%$ manufactured arguments. Finally, a taxonomic technique appears, based on the provided list of standard fallacies. Students are given a range of arguments identified as mistaken and asked to indicate which fallacy label from the taxonomy accounts for the mistake. Or, alternatively, the exercise provides a range of arguments that may or may not be mistaken but does not discuss the acceptable counterparts for fallacies listed in the taxonomy.

An overwhelming majority of textbooks that cover fallacies of argumentation employ not just a necessary minimal oppositionality but foster the Adversary Method in their presentation. I maintain that a given textbook fosters the Adversary Method if it employs at least three of the following practices, which I address in increasing order of complicity: (a) neglect of the potential for argument repair; (b) predominant use of examples that are either very short or decontextualized; (c) manufactured examples; and, most deeply entrenched in the Adversary Method, (d) exercises that employ what I 
call the "taxonomic technique", that assume that the presence of an argument scheme that may be fallacious always makes an argument fallacious. To trace the presence of these elements, I have analyzed 30 textbooks. All of them are critical thinking textbooks currently in print that discuss fallacies and that could be examined in a limited time period. The results of this analysis are shown in Table 1, beginning on the next page. The table summarizes the problematic presentation of fallacies in a range of textbooks, with columns indicating (a) less problematic through (d) most problematic.

My sampling method, although driven by time constraints, accounts adequately for those textbooks most readily available, and leaves out those with no substantial discussion of fallacies and those outside the discipline of philosophy. Some texts, like Romain, 1997, address fallacies merely in passing as misuses of acceptable approaches to argumentation that are the book's central focus. Textbooks with a focus on fallacies in the disciplines of rhetoric and composition (e.g. Inch and Warnick 2002) do not share the problematic practices that concern me. And in philosophy there are also several exceptions, made so by their exhibiting no more than two of the questionable features, almost all from the authors who are scholars in argumentation and informal logic. ${ }^{10}$

There might be many motivations for the individual practices that I critique, motivations that are part of the Paradigm's ideology I will consider as I explore each practice in section 5 . Then, in section 6 , I will consider further reasons these practices may be attractive. The tangential attractions could provide alternate justification for the use of one or two of these practices, except for the taxonomic technique because it wholly implies the Adversary Method. So, it seems fair to require that three of the four problematic practices must be present before saying that the presentation of fallacies

\footnotetext{
${ }^{10}$ Exceptions include textbooks by Bickenbach and Davies (1997), Epstein (2006), Govier (2010), Johnson and Blair (2006), Tindale (2007b), all of whom are scholars in argumentation and informal logic. Boss (2010) is another exception written by a scholar of moral reasoning who engages feminist issues. Only three philosophy textbooks-Walton, Woods, and Irvine (2004), Copi and Cohen (2005), and Engel (2000) - that my analysis reveals as employing the Adversary Method (and so that appear on the Table) have authors who are scholars in the field; and these are certainly among the borderline cases. The worst practice, the taxonomic technique, does not appear in Walton, Woods, and Irvine (2004), and many longer, contextualized, and authentic examples can be found in Engel (2000). Engel's and Copi and Cohen's (2005) belong to an early generation of textbooks, which explains why they are out of step with recent scholarship. To assess the authors' scholarship I consulted the current on-line edition of The Philosopher's Index, looking for at least one publication in informal logic or argumentation to count as scholarship in the area, but finding a substantial gulf. Those whom I count as scholars in the field all have several publications in the area, whereas the remaining authors have no such publications.
} 
exhibits the Adversary Method. (The taxonomic technique never occurs without support by at least two more of these practices.)

Table 1. The Presentation of Fallacies in Critical Thinking and Logic Textbooks

Indicates that the practice covered in the column is not used in the textbook examined in that row

\begin{tabular}{|c|c|c|c|}
\hline $\begin{array}{l}\text { (a) No discussion } \\
\text { of argument } \\
\text { repair }\end{array}$ & $\begin{array}{l}\text { (b) Short or de- } \\
\text { contextualized } \\
\text { examples }\end{array}$ & $\begin{array}{l}\text { (c) Manufac- } \\
\text { tured examples }\end{array}$ & $\begin{array}{l}\text { (d) Exercises use } \\
\text { taxonomic tech- } \\
\text { nique }\end{array}$ \\
\hline $\begin{array}{l}\text { Bassham, Irwin, } \\
\text { Nardone, and } \\
\text { Wallace (2005) }\end{array}$ & $\begin{array}{l}\text { Bassham, Irwin, } \\
\text { Nardone, and } \\
\text { Wallace (2005) }\end{array}$ & $\begin{array}{l}\text { Bassham, Irwin, } \\
\text { Nardone, and } \\
\text { Wallace (2005) }\end{array}$ & $\begin{array}{l}\text { Bassham, Irwin, } \\
\text { Nardone, and } \\
\text { Wallace (2005) }\end{array}$ \\
\hline Burton (2002) & Burton (2002) & Burton (2002) & Burton (2002) \\
\hline Carey (2000) & & Carey (2000) & Carey (2000) \\
\hline $\begin{array}{l}\text { Copi and Cohen } \\
\text { (2005) }\end{array}$ & $\begin{array}{l}\text { Copi and Cohen } \\
(2005)\end{array}$ & & $\begin{array}{l}\text { Copi and Cohen } \\
(2005)\end{array}$ \\
\hline \multirow[t]{2}{*}{$\begin{array}{l}\text { Copi, Cohen and } \\
\text { Flage (2008) }\end{array}$} & $\begin{array}{l}\text { Copi, Cohen and } \\
\text { Flage (2008) }\end{array}$ & $\begin{array}{l}\text { Copi, Cohen and } \\
\text { Flage (2008) }\end{array}$ & $\begin{array}{l}\text { Copi, Cohen and } \\
\text { Flage (2008) }\end{array}$ \\
\hline & Damer (2005) & Damer (2005) & Damer (2005) \\
\hline Dayton (2010) & Dayton (2010) & Dayton (2010) & Dayton (2010) \\
\hline Engel (2000) & Engel (2000) & Engel (2000) & Engel (2000) \\
\hline \multirow[t]{2}{*}{ Flage (2004) } & Flage (2004) & Flage (2004) & Flage (2004) \\
\hline & Gula (2006) & Gula (2006) & NO EXERCISES \\
\hline $\begin{array}{l}\text { Hughes and Lav- } \\
\text { ery (2008) }\end{array}$ & $\begin{array}{l}\text { Hughes and Lav- } \\
\text { ery (2008) }\end{array}$ & $\begin{array}{l}\text { Hughes and Lav- } \\
\text { ery (2008) }\end{array}$ & $\begin{array}{l}\text { Hughes and Lav- } \\
\text { ery (2008) }\end{array}$ \\
\hline Kenyon (2008) & Kenyon (2008) & Kenyon (2008) & NO EXERCISES \\
\hline Leblanc (1998) & Leblanc (1998) & Leblanc (1998) & Leblanc (1998) \\
\hline Lee (2002) & Lee (2002) & Lee (2002) & \\
\hline $\begin{array}{l}\text { Moore and Parker } \\
(2007)\end{array}$ & $\begin{array}{l}\text { Moore and Parker } \\
(2007)\end{array}$ & $\begin{array}{l}\text { Moore and Parker } \\
(2007)\end{array}$ & $\begin{array}{l}\text { Moore and Parker } \\
(2007)\end{array}$ \\
\hline $\begin{array}{l}\text { Reichenbach } \\
\text { (2001) }\end{array}$ & & $\begin{array}{l}\text { Reichenbach } \\
\text { (2001) }\end{array}$ & $\begin{array}{l}\text { Reichenbach } \\
\text { (2001) }\end{array}$ \\
\hline
\end{tabular}


Fallacies Approach to Argument Evaluation

\begin{tabular}{|l|l|l|l|}
\hline $\begin{array}{l}\text { Rudinow, Barry } \\
\text { and Letteri } \\
(2008)\end{array}$ & $\begin{array}{l}\text { Rudinow, Barry } \\
\text { and Letteri (2008) }\end{array}$ & $\begin{array}{l}\text { Rudinow, Barry } \\
\text { and Letteri (2008) }\end{array}$ & $\begin{array}{l}\text { Rudinow, Barry } \\
\text { and Letteri } \\
(2008)\end{array}$ \\
\hline Saindon (2008) & Saindon (2008) & Saindon (2008) & Saindon (2008) \\
\hline $\begin{array}{l}\text { Schick and } \\
\text { Vaughn (2005) }\end{array}$ & $\begin{array}{l}\text { Schick and } \\
\text { Vaughn (2005) }\end{array}$ & $\begin{array}{l}\text { Schick and } \\
\text { Vaughn (2005) }\end{array}$ & $\begin{array}{l}\text { Schick and } \\
\text { Vaughn (2005) }\end{array}$ \\
\hline $\begin{array}{l}\text { Schwarze and } \\
\text { Lape (2000) }\end{array}$ & $\begin{array}{l}\text { Schwarze and } \\
\text { Lape (2000) }\end{array}$ & $\begin{array}{l}\text { Schwarze and } \\
\text { Lape (2000) }\end{array}$ & $\begin{array}{l}\text { Schwarze and } \\
\text { Lape (2000) }\end{array}$ \\
\hline $\begin{array}{l}\text { Teays (2006) } \\
\text { Teays (2006) }\end{array}$ & Teays (2006) & Teays (2006) \\
\hline $\begin{array}{l}\text { MacDhn and } \\
\text { (2008) }\end{array}$ & $\begin{array}{l}\text { Vaughn and } \\
\text { MacDonald } \\
\text { (2008) }\end{array}$ & $\begin{array}{l}\text { Vaughn and } \\
\text { MacDonald } \\
\text { (2008) }\end{array}$ & $\begin{array}{l}\text { Vaughn and } \\
\text { (2008) }\end{array}$ \\
\hline Wilson (1999) & Wilson (1999) & Wilson (1999) & \\
\hline $\begin{array}{l}\text { Woods, Irvine } \\
\text { and Walton } \\
\text { (2004) }\end{array}$ & $\begin{array}{l}\text { Woods, Irvine and } \\
\text { Walton (2004) }\end{array}$ & $\begin{array}{l}\text { Woods, Irvine and } \\
\text { Walton (2004) }\end{array}$ & \\
\hline
\end{tabular}

\section{The implication of the Adversary Method}

In this section I argue that each of the four practices surveyed in Table 1 implicates the Adversary Method. Alternatives to the goal of defeat are ignored in textbooks that neglect the possibility of argument repair. The other three problematic practices restrict the discourse, thus facilitating the goal of defeat.

No suggestion of argument repair. Current scholarship and the occasional textbook (Damer 2005, Gula 2006, Johnson and Blair 2006) recognize that the presence of a fallacy may not indicate a fatal flaw in an argument. ${ }^{11}$ Some fallacious arguments can be repaired; the burden of proof that was not fulfilled may become fulfilled. When this possibility is ignored, the fallacy demonstration is treated as defeating the argument. Taking defeat to be the goal of argumentation at the very least supports the operation of the Adversary Method, even though that goal need not involve the Method's typical constraint of discourse; it is more than minimally oppositional. Addressing argument repair is one way to hedge against the Adversary Method's dominance. The Method does not appear as the paradigm of reasoning when a textbook considers as

\footnotetext{
${ }^{11}$ Damer (2005) also recognizes fallacies of rebuttal, providing further dialectical context for fallacy allegation. Yet these fallacies of rebuttal are impossible to assess in brief examples typical of textbooks, as my students have convinced me.
} 
part of the dialectical context goals for argumentation aside from defeating others' views.

Short and decontextualized examples. Short examples and examples abstracted from their dialectical contexts become more vulnerable to fallacy allegations, because this practice minimizes the burden of proof on the person who alleges that a fallacy was committed. While fallacy allegation generally opens up responsibility for the burden of proof that may be taken up by the arguer or the critic, short and decontextualized examples assist with negative interpretation, making it easier for critics to defend their fallacy allegations and fulfill their burden of proof. Textbooks generally employ short passages of just a few sentences. Short examples increase the control that instructors and textbook authors have over student interpretation by limiting the elements that require interpretation. Such constraint helps avoid the situation in which students' varying interpretations of dubious arguments suggest that different fallacies are the source of the problem, or the students identify merit in an argument that the instructor/author intends to demonstrate a fallacy. ${ }^{12}$ Such inconvenient interpretations are less available for short passages with fewer elements to play with. So, focusing on narrow interpretations facilitates the Adversary Method's goal of defeating others' arguments.

Likewise commonplace and similarly problematic is abstracting arguments from the dialectical contexts in which they occur, representing them as isolated premise-conclusion complexes. The dialectical context of the audience suggests a specific situation, and reasons for accepting the argument. Directly requiring students to discuss how to defend the argument, as do Rudinow, Barry and Letteri (2008), encourages students to contextualize an argument and treat it fairly. More typically decontextualized presentation, just like short examples, limits the possibility for sympathetic interpretation, undercuts "the principle of charity,"13 and makes it easier to defeat arguments. Such presentation ignores the dependence of an argument's meaning on its intended audience, and treats the reasoning as standing on its own. This practice of abstraction denies the rhetorical aspect of fallacy allegation that involves the audience-whether in the original context or the audience of students - and such possibilities often require working through the variability of interpretation.

Teaching the fallacies approach to argument evaluation by extracting arguments from their original discourse makes the person who alleges that a fallacy was committed accountable only to the

\footnotetext{
12 David Hitchcock (1995) explains how frustrating the potential for differing interpretation can be in teaching fallacies.

${ }^{13}$ The principle of charity is a rule for interpretation that requires the audience to view an argument in such a way as to make it appear most reasonable, giving the arguer the benefit of the doubt when he or she is unclear.
} 
interpretations provided by the textbook or instructor. An allegation that an argument commits a fallacy is an audience response-even if the students are the only audience-and so fallacy allegation should engage students of argumentation with the dialectical and conversational context. Conversation is in play around any argument; and in suggesting that a fallacy was committed, the audience resists the argument. A fallacy allegation brings into question the nature of the discussion, and draws attention to what Walton (1997, 1995) describes as the background conversation, a discussion that people engage by addressing the critical questions associated with the particular fallacy label.

Deferring to the predetermined interpretation becomes part of the skill set being learned when exercises are short or decontextualized. Such pedagogical practices not only minimize responsibility for fallacy allegation, but substitute responsibility to the textbook and instructor for responsibility to the arguer. Because there is no imaginable recourse from an arguer in an abstract presentation with no "real world" audience, the argument is more likely to be defeated, which makes the instructor's job easier. Yet, it eliminates the valuable pedagogical potential of working through students' own interpretations and addressing the support for students' interpretations by attention to the textual and rhetorical contexts of the arguments.

Manufactured examples. Many textbook authors manufacture their own examples, one actually devises a "cast of characters" in a cartoon world (Epstein 2006), and many textbooks repeat each other's examples. Manufactured examples present the same problem as do short or abstract examples in that they remove contextual elements from consideration. Whereas names and places suggest faces, real people with real problems and earnest concerns that deserve recognition, there is no motivation for students to repair the argument and little claim by the fictional or absent arguer to be interpreted charitably. The author or instructor controls the interpretation by inventing cases to illustrate the categories being taught. By contrast, real arguments are often too complex to be easily susceptible to refutation, especially those arguments that are sufficiently sophisticated to be published. Although the internet is proving to be a great source of citable fallacies because the short format of blogs and discussion forums lends itself to the production of fallacies in succinct form, its unique lack of editorial control makes the internet exceptional among citable sources.

Interpreting authentic arguments frequently requires considering the source from which the argument is drawn-the author, the publication, the date, and further background detail. The contextual baggage of real arguments thus brings with it pedagogical complications: attending to author, audience, venue, and genre requires students to have a social and stylistic awareness that is quickly 
dated, and an historical understanding that they may lack, both of which vary even within North America. So, for instance, specifically Canadian editions of U.S. textbooks are useful for Canadian students (e.g. Rudinow, Barry and Letteri 2008, Vaughn and MacDonald 2008). The pedagogical complexities of using real examples make attractive the comparative ease of using manufactured examples that can be tailored to avoid the worst difficulties of interpretation. However, artificially restricting possible interpretations follows suit with the enforcement of narrow categories to facilitate defeat of an argument - and illustrates how the Adversary Method operates.

The taxonomic technique. The "taxonomic technique - as I use this term-begins with assumed fallaciousness and aims at rationalizing the argument's defeat by identifying it according to the fallacies taxonomy. This technique limits the students' burden of proof to picking out the relevant argument scheme, tacitly suggesting that all instances of the argument scheme are fallacious. While we need not expect all textbook authors to use the language of argument "schemes,"14 we must expect textbooks to acknowledge conditions in which the presumptive reasoning named by a fallacy is acceptable. Otherwise, the message to students is that the scheme is never justified.

Identifying errors by scanning for argument schemes is the goal of the taxonomic technique. Such games of "pin-the-fallacyon-the-argument" 15 are common practice in critical thinking courses in Canada and the United States, and in the teaching of forensic argumentation or formal debate in the United States. Textbooks typically provide answers, and rarely acknowledge the broad ambiguities one must negotiate in working through interpretations, or the role of background knowledge in providing interpretation.

The taxonomic technique removes much of the burden of proof from the person (including the instructor) who alleges that a fallacy has been committed. The person simply uses the fallacies taxonomy to evaluate the argument, to decide why the argument is taken to be weak. This assumption deflects, rather than pursues, the responsibility of engaging another's argument. In fair practice, among equals, the burden of proof to demonstrate the weakness or strength of the presumption (characteristic of that form of argument) opens up when a critic alleges that a fallacy was committed. That ambiguous responsibility for burden of proof that comes with fallacy allegation is resolved by the taxonomic technique returning the burden of proof to the arguer. If a potentially fallacious argu-

\footnotetext{
${ }^{14}$ Not all current fallacies scholarship uses the notion of argument schemes to account for the exceptions to fallacies. A more direct alternative is to employ critical questions to qualify the application of fallacy labels, but to do so is to recognize acceptable correlates of the argument scheme.

${ }^{15}$ Thanks to Ralph Johnson for this description.
} 
ment scheme can be identified in an argument then the argument is dismissed, without any question about whether this is one of the acceptable uses of that argument scheme.

The taxonomic technique trains students in rationalizing the defeat of arguments by employing the Adversary Method. Constraining discourse by ignoring the possible cogency of argument schemes that are sometimes involved in fallacies involves key problematic factors of the Adversary Method as described by Moulton. That is, defeat of the argument is assumed, the set categories restrict the conditions of dialogue, the argument is either categorically acceptable or unacceptable, and particular argument schemes are deemed to be categorically unacceptable.

\section{The attraction of the Adversary Paradigm}

The predominance of the Adversary Method in textbooks might be explained in many ways not directly part of providing a severe interrogation of others' arguments. Additional factors that make the specific practices and the general Method attractive and encourage their use are the subject of this section. Some influencing factors are the demands of teaching, the dynamics of social position among philosophy faculty, and the academic marginalization of informal logic and argumentation theory in the face of the prestige of the philosophical tradition. Yet these explanations are not sufficient; we also need to consider the fact that the Adversary Method operates as the paradigm of philosophy.

I have great sympathy for the difficulty of teaching fallacies ${ }^{16}$ and have in the past both desired and sought out critical thinking textbooks that had easily testable exercises, such as those using the taxonomic technique, and those with exercise examples that did not invite multiple interpretations - short, decontextualized, or manufactured. Control over interpretation is especially valuable for parttime and junior instructors, who have their own uncertain learning curves to handle, and who may have lower status in the classroom than more experienced instructors. If women, people of colour, and other socially marginalized people hold less authority in front of the classroom than white men of privilege, that lack of authority may make the most controlled exercises especially appealing.

Manufactured examples can be attractive because they avoid how cases from current affairs become rapidly dated. Likewise, many of the manufactured examples seem to represent arguments too weak to make it to print, but that are the sort of argumentation

\footnotetext{
${ }^{16}$ J. Anthony Blair (1995) and David Hitchcock (1995) discuss a great range of the pedagogical challenges in taking up pro and con positions on the value of teaching fallacies as a method of argument evaluation.
} 
one hears in conversation. Everyday conversations deserve our attention and manufacturing representations of them provides practice that is valuable for students learning to interpret arguments they will face in their own discussions. Simple arguments that operate as exemplars are pedagogically important in the explanation of the fallacies and perhaps in a few warm-up exercises to give students the feel for identifying the particular argument scheme and distinguishing among the fallacies.

The systemic problem is that limited experience with the course material is exceptionally common among critical thinking instructors. Argumentation and informal logic are rarely part of graduate training, despite their omnipresence in undergraduate teaching that the training is supposed to support. A desire to compensate for inexperience with controlled pedagogical methods helps explain why the Adversary Method predominates in textbooks. It helps instructors who are likely to be untrained in the area, though they are quite certainly trained in the Adversary Method. In addition, instructors may feel responsible for teaching fallacies in the "classic" fashion, rather than exploring the nuances of fallacy scholarship. However, they may have picked up on the ill fit of fallacies with the more systematic and theoretically supported alternative ways to analyze arguments, and they then choose to avoid the intricate frustrations of student interpretation by rushing through teaching fallacies as a means of argument evaluation.

Since the paradigmatic status of the Adversary Method is unwarranted, likewise unwarranted is the pervasive epistemic authority of the Method's interpretation of fallacies, the Method's prevalence in the fallacies pedagogy, and in the (resulting) popular understandings of fallacies. Students come to believe that there exists little, if any, need to defend the application of fallacy labels except to distinguish among them, and they come to value the Adversary Method and consider it logical. The analysis seems aristocratic, in the sense of sophisticated. In fact, it is feudal in its homage to outdated approaches, and paternalistic in suppressing the variability of interpretation that argumentation involves when practiced outside of the rarified context of philosophy, and sometimes within philosophy. Rationalizing this restriction by appealing to tradition leads us back to the Adversary Paradigm as an ideal of philosophy - an ideal that, unfortunately, prevails despite its neglect of students' practical needs.

\section{The discursive effects of the Adversary Paradigm}

The fact that the Adversary Method remains in operation as a paradigm of reasoning has a number of unjust and damaging consequences. This Paradigm affects debating and legal discourse, and 
general discourse about reasoning inside and outside of universities and colleges. In its place, we need to foster other styles of argumentation in order to allow a range of people equal participation in philosophy and in argumentation more generally. Admittedly the Adversary Method and oppositional modes of reasoning do not currently dominate philosophy and argumentation to the extent that they did a few decades ago. So, it is useful to distinguish the "minimal" opposition of adopting a contrary position to a stated position from the unnecessarily confrontational "ancillary" academic culture of hostility and rudeness that has become less prevalent (Govier 1999). Most dialectical accounts of argumentation assume minimal opposition or adversariality, and objecting to a line of argumentation is integral to the fallacies approach to argument evaluation, as I explained above. Aiming to defeat arguments by narrowing discourse, as in the Adversary Method, is something else altogether, and it has a chokehold on the fallacies approach.

The Adversary Method is so deeply ingrained in the discipline of philosophy that it operates as a Kuhnian paradigm - a model, or overarching framework that governs a customary method (Moulton 1983, Kuhn 1996). While we might grant Thomas Kuhn's position that paradigms of reasoning are productive in science, and that philosophy benefits from the rigor of having a paradigm, the Adversary Paradigm creates problems in philosophy. I will argue in this section that the heavy discursive influence of epistemology via critical thinking education gives the Adversary Paradigm a broad influence that reinforces forms of social exclusion and dominance. Admittedly, redressing sociopolitical exclusion -inside and outside of philosophy - sometimes requires an oppositional stance. However, the Adversary Paradigm excludes any form of reasoning that does not conform to the Adversary Method, an exclusion that reinforces sociopolitical marginalization.

The comprehensiveness of any Kuhnian paradigm rules out other ways of conceptualizing and practicing reasoning, and this is especially the case with the Adversary Paradigm.

Philosophy, in its attention to extreme positions because they are extreme, presents a distorted picture about what sorts of positions are worthy of attention, giving undo [sic] attention and publicity to positions merely because they are those of a hypothetical adversary's [sic] and possibly ignoring positions which make more valuable or interesting claims. (Moulton 1983, p. 158)

The Adversary Paradigm excludes consideration of background reasons and relationships among systems of belief. Such narrowness is contrary to philosophy's broad discursive significance as a creator and investigator of norms and ideals. Plus, there are many 
purposes people may have in expressing premises as support for conclusions: to inform the uninitiated, to explain, "to figure something out for oneself, to discuss something with like-minded thinkers, to convince the indifferent or the uncommitted" (Moulton, 1983, p. 159), and only sometimes to defeat others. Arguments and, more particularly, the making of arguments ${ }^{17}$ may have no intrinsic function (Goodwin 2007) or use (Blair 2004), and the variety of specific purposes that arguments serve disappear under the Adversary Paradigm.

Because the Adversary Method aims at defeating an interlocutor, its exclusions privilege those with the most social power who can muster greater resources to suppress the views of others regardless of the quality of the others' reasons. Sometimes the test comes down, unfortunately, to who shouts the loudest, or whose shouting can silence everyone else, and on who gets to interpret the ensuing silence.

In addition to the sheer weight of cultural resources, the discursive style associated with one's social situation empowers some people more than others. Women, people of color, or those with only basic education face special difficulties with the Adversary Method. The Method enforces oppositional norms associated especially with masculinity in the culture of the global North, and contrasts with norms of femininity, as well as with styles of reasoning in other marginalized groups on both a local and global scale. The "curious coincidence" in styles of reasoning valued among the underclasses (Harding 1986, Ch. 7) results, at least in part, from the need to appease those in power. "If one's success depends on other parties, it is likely to be far wiser to appear friendly than to engage in aggressive behaviour" (Moulton 1983, p. 151; emphasis in original). ${ }^{18}$

Consider specifically that men and women, or boys and girls, are differently able to access modes of communication that are entwined with norms of masculinity and femininity, although there is no reason to posit significant basic, essential, or innate differences between male and female reasoning capacities. ${ }^{19}$ The oppositional

17 Daniel O'Keefe (1977) distinguishes between argument as a premiseconclusion complex and the speech act that expresses it, which is "making an argument."

${ }^{18}$ The value of aggression on Moulton's analysis is tied up with the identity of theorists as men, also a concern for Lorraine Code (1995, p. 12), which on Alcoff's analysis is the second political dimension of epistemology (1993, pp. 6972), the dimension of bias. That dimension is beyond the scope of this paper, but it complicates the discursive effects regarding (non-white, non-middle class, non-Anglophone) non-men that I am addressing.

${ }^{19}$ Despite the endless study of gender differences in cognition, the differences are persistently insignificant. (A. Fausto-Sterling, Myths of gender: Biological theories about men and women, revised edition, Basic Books, 1992, pp. 13-60.) 
style of reasoning because of its association primarily with masculinity may be especially attractive to men, and that may explain why negative evaluations are better accepted when they come from men (Sinclair and Zunda 2000). ${ }^{20}$

An oppositional stance can be valuable for marginalized groups, and some individuals living under oppression excel at and take substantial pleasure in intellectual sparring; they may favor an oppositional style and employ it to emancipatory ends. After all, Judith Jarvis Thomson's employment (1971) of the Adversary Method defends a feminist perspective on abortion: that women's right to control their own bodies is stronger than the right to life. Addressing power differentials among people and working for liberation regularly demands an oppositional stance.

However, the assumed oppositionality of the Adversary Method imposes a narrow field of discourse that precludes demonstration of the broad reasons behind liberatory movements, and exploration of available alternative sensibilities. For example, feminist and other liberatory epistemologists regularly receive demands from "mainstream" epistemologists to address traditional thought experiments taken to be definitive of the possibilities for knowledge. These mainstream epistemologists ignore how different scholarly histories, as well as specific concrete problems and conditions of knowing, inform the liberatory analysis.

\section{Authoritarian popular pedagogy}

In this section I consider the authority of the Adversary mode of the fallacies approach granted by the discursive effect of critical thinking pedagogy. An account of authority in this arena allows us to distinguish, yet recognize the connections among, various dimensions of the discursive impact of critical thinking pedagogy. Considering discursive impact as a matter of authority encourages us to consider how the created epistemic authority might relate to other forms of authority. Because popular pedagogy has not responded to the academic field of argumentation theory and informal logic, it is epistemically authoritarian, in neglecting the available reviews of its standards. Its employment of the Adversary Paradigm also reinforces unjust forms of sociopolitical marginali-

\footnotetext{
Apparent differences between the genders are easily explained by socialization and education.

${ }^{20} \mathrm{I}$ avoid attributing different patterns of reasoning to different social groups but emphasize how styles of reasoning are valued, and which are effective for people in different social situations and with different histories.
} 
zation. Evidence of this discursive effect is found in the use of the fallacies approach to silence feminist philosophers. ${ }^{21}$

The epistemic (or cognitive) authority of expertise, and the administrative authority of command are well recognized as specific forms of authority. One further type of authority is dignity; it also claims our respect, and was identified as a basis for reasoning by John Locke and Richard Whately in their discussions of ad verecundiam reasoning. These discussions are the basis of the contemporary fallacy label of "appeal to authority." Dignity was, in fact, their primary understanding of authority, making it quite different from our contemporary understanding of authority that focuses on expertise and command (Hansen 2006, Goodwin 1995). My primary concern is with epistemic authority as it relates to fallacies, but I will consider the authority of dignity in the final section of this paper.

Authority, in whatever form, provides the power to wield rhetorical silence. Such silences are ambiguous and require that we specify their meanings; otherwise they leave us anxious (Glenn 2004, p. 11). The meaning of a specific silence and the force of a call for silence are controlled by those in power (Glenn 2004); that control, in turn, is part of what makes those people authorities. Discursively, authorities act as reasons, providing the place where explanation stops (Hanrahan and Antony 2005, p. 69). From infancy to citizenship, the authorities that we encounter direct our negotiation with our culture by informing and directing us, but authority also marks places where no further information or direction may be had. The reliability of an authoritative source is beyond immediate question. Whether we are children, or students, or citizens trying to complete income tax forms, the questions that can be posed to an authority are limited because authorities themselves function as reasons.

Both the people who use the fallacies approach and the fallacies approach as a system can have authority and wield the power to silence. In many textbook and scholarly examples, the holder of authority is inanimate: a machine, schedule, tradition, or field of expertise. As Jim Mackenzie writes, "[whether] the conditions under which ' $A$ says that $p$ ' gives us reason to accept that $\mathrm{p} .$. depends both on the relation of $A$ to ' $p$ ' and on the nature of ' $p$ ' itself" (1988, p. 60). Moreover, accepting depersonalized authorities be-

${ }^{21}$ The value of the feminist analysis in revealing this perversion of epistemic authority bears out the central claim of feminist standpoint theory that a feminist perspective is epistemically advantageous (Hartsock 1983; Harding 1986; 1991; Hundleby 1997). The feminist perspective does not provide epistemic justification but acts as a heuristic that reveals problems ripe for epistemological analysis. 
comes second nature in a technological society, as Lorraine Code argues (1995, p. 21).

The authority to silence others by, in particular, stopping an inquiry unifies our discussions and makes them effective by orienting them around specific goals, such as keeping records, making dinner, learning, or reaching agreement. A democracy with many voices and perspectives but without an organizing authority is hopelessly inefficient. For a society to be functionally democratic it needs systems of reasoning that support democratic goals, and people who can manage those systems. Other communal goals, such as producing scientific understanding, require the evaluation of argumentation. Argument evaluation can also be an individual personal concern, as it is for many students who simply want to improve their reasoning.

The fallacies approach to argument evaluation has a unique discursive authority relative to other forms of argument evaluation and other technical skills. Other forms of argument evaluation can direct dialogue, but they require a greater degree of descriptive interpretation, making them more open to interrogation than the shorthand of fallacy names. Any labels or jargon can be used for bullying; but the fallacies approach lends itself especially well to that type of abuse because of its status as logic, its historical pedigree, its pride of place in liberal and legal education, and its legitimate function of redirecting discourse. All these factors grant authority.

Yet, the version of the fallacies approach that emerges out of popular philosophical pedagogy does not deserve the epistemic authority it receives, either as logic, or in specific discursive situations when it shifts the burden of proof back to the arguer. The authority of the popular pedagogical treatments is illegitimate because of the priority it gives to the Adversary Method. This giving of priority to the Method - analyzed in Table 1-occurs almost exclusively in textbooks by authors who are not current scholars in argumentation and informal logic, whereas such priority is not evident in textbooks by authors who are scholars in the field.

Philosophers' inattention to the relevant scholarship makes their discursive impact authoritarian rather than authoritative. As Rebecca Hanrahan and Louise Antony argue, authority becomes authoritarian when it persists without monitoring, evaluation, and adjustment. The proper exercise of authority requires: (1) appropriate public restrictions on its legitimate usage; and (2) procedures for the review or redress of its usage (Hanrahan and Antony 2005, p. 72). As a place where explanation stops, the popular fallacies approach is quite public: it is part of our education system, and published in many popular textbooks, sometimes at moderate prices. Further, one would expect that as an academic subject area it would undergo regular review and redress. 
Reviewing the status of particular fallacies is a large component of fallacies scholarship, and argumentation theorists have tested and reformulated general accounts of fallacy. Thus at both the particular and systematic levels, the epistemic authority that the fallacies approach can is evaluated and improved. Yet this sort of epistemological review remains unheeded when authority is granted to publish textbooks or teach courses, as we see from the outdatedness of typical instruction methods.

Thus, the Adversary Paradigm perverts the epistemic potential of the fallacies approach. Professors and students alike find that the taxonomies help identify mistakes in argumentation that we regularly encounter. This subjective warrant and anecdotal evidence has been sufficient to perpetuate the pedagogical tradition surrounding the fallacies approach, which explains why so many instructors and textbook authors simply teach what they learned as undergraduates. Such a weak scholarly foundation corrupts pedagogy, and systematically perpetuates ignorance.

The perversion of this particular authority takes on a distinctly political cast (beyond the internal politics of philosophical subdisciplines) because the popular version of the fallacies approach is most persuasive in the hands of people considered who already have authority in some other form. Thus popular fallacies pedagogy has the discursive effect of reinforcing existing forms of social privilege. Men and white folks will be more effective in using the fallacies approach to defeat arguments because, as a group, such people are more able to control which discourse becomes the lingua franca for testing reasoning. Correspondingly disempowered will be those lacking substantial power, such as women in certain contexts and visible minorities. Independently of the evils of the Adversary Paradigm, those who lack authority are especially dependent on experts (Code 1993, p. 181), and thus vulnerable to merely specious expertise and systems of expertise. This is all the more reason to demand recognition of varieties of expertise and varieties of methods for argument evaluation.

A distinctive example of the use of the Adversarial version of the fallacies approach to bully and silence can be found in the way that accusations of genetic fallacy were leveled summarily at feminist philosophy from the 1970s through the 1990s. Feminists appealed to gender as a salient factor in the history of philosophy and philosophical theorizing, a factor that constituted an exception to the prohibition by the genetic fallacy (at least as popularly understood) against considering the sources of ideas. Yet fallacy allegation enforced this prohibition by narrowing philosophical discussion, and facilitating dismissal of feminist philosophy.

Demonstrating the social situations of philosophers to be relevant to the substance of their views was the trajectory of much feminist philosophical work, but in its novelty the feminist work 
violated the accepted categories. There was no "rhetorical space," in Code's words, ${ }^{22}$ to address the accusations because of the extent of women's marginalization in philosophy - and even more so in epistemology and logic. ${ }^{23}$ This marginalization rendered feminist philosopheres unable to authoritatively interpret the rhetorical silence surrounding a fallacy allegation, unable to direct the discussion. The interpretation of more socially powerful speakerstypically male philosophers - played into the paradigmatic status of the Adversary Method and lent finality to the allegation of genetic fallacy. As Margaret Crouch (1991) argues, the scholarship on the genetic fallacy shows that the description is misapplied to feminist philosophy because feminists provide reasons to support their genetic appeals. Feminists addressed the critical questions and fulfilled the burden of proof associated with the argument scheme, if we would describe the feminist methods in the terms of argumentation theory and informal logic.

\section{Conclusion: Beyond the paradigm}

An evolution of the fallacies approach to argument evaluation would make its evaluations more fully authoritative. My criticism has been that popular versions of the fallacies approach are out of touch with current scholarly standards, both in argumentation theory and feminist epistemology. To conclude my discussion, I will first consider the pursuant pedagogical options, and then I will consider the epistemological impact of rejecting the operation of paradigms in the discipline of philosophy. I will finish by recommending resources in the fallacies approach for liberatory epistemology.

Both limited teaching resources and the entrenchment of the Adversary Method make it difficult to reform fallacies pedagogy. Adequate teaching of the fallacies approach to argument evaluation requires more than the few standard classes or chapters (Blair 1995). A pedagogy for fallacies more in line with the current scholarship demands much more in terms of time and the other resources provided by courses and textbooks. Therefore, in teaching argument evaluation the choice will be between using a general fallacies framework (e.g. Johnson and Blair 2006, Tindale 2007b),

\footnotetext{
${ }^{22}$ Code's notion of "rhetorical space" refers to "how domains of inquiry are staked out so that certain things can be said and others cannot, not because of any explicit prohibition or because they are clearly beside the point, but because of ossified perceptions about what the point is; because they do not fit, do not mesh with what participants in the established discourse know how to respond to - and because of a reluctance to reconsider those boundaries" (1995, p. 4).

${ }^{23}$ Most feminists in philosophy have been women, and during the last quarter of the twentieth century most women in philosophy engaged to some extent in feminism.
} 
or not addressing fallacies at all but using some other approach (e.g. Walton 2006b), or perhaps only mentioning fallacies as exceptional problematic cases of otherwise acceptable argument strategies (a small number of current textbooks not included in my analysis). Yet in all philosophy classes, not just those designed to teach critical thinking, we can stress the value of argument repair, and this alone can defy the authority of the Adversary Paradigm. ${ }^{24}$

The choices that individual instructors make of textbook and course format will help reform the practice of fallacy allegation, but the problem of unscholarly and out-of-date textbook pedagogy (despite multiple editions!) demands more substantial and systematic change. Of course, textbook publishers should apply stricter standards to their authors, and although I have little hope of directly persuading publishers, a shift in the demand would influence what they put on the shelves. My audience here is academics, and philosophers in particular, who I hope will take greater care in their power over how critical thinking and fallacies are taught and how instructors are assigned. We must demand instructors and textbooks with current scholarly authority, and challenge the view that any philosopher is competent to teach critical thinking. The lack of expertise generally tolerated for instructors in critical thinking courses seems much greater than in other areas of philosophy. There rightly would be an uproar in other academic fields, and such lack of expertise should not be tolerated in argumentation pedagogy either.

A few textbooks, for instance, Edward Damer's Attacking faulty reasoning (2005), Brian Epstein's Critical thinking (2002) and Christopher Tindale's Fallacies and argument appraisal (2007b), suggest ways one can respond to fallacy allegations. The treatment of fallacy allegation as only a first step toward improving reasoning - whether one's own or others' - is socially engaged. Plus, it is a less oppositional (though of necessity "minimally oppositional") approach to argumentation than the Adversary Method. These textbooks still recognize that sometimes arguments can and should be defeated. In that acknowledgement, they recognize multiple purposes that argumentation can have.

Such texts illustrate the epistemological treatment of "reasoning with" identified by Phyllis Rooney as an alternative to "arguing against." Epistemological considerations may help philosophers adjust their expectations of fallacies pedagogy and recognize the multiple purposes of argumentation. Rooney suggests that we consider argumentation in the context of the general epistemological language of discussion and reasoning "with" people and views, as well as the joint venture of knowledge-seeking. This less oppositional way of speaking extends quite comfortably and naturally to

\footnotetext{
${ }^{24}$ Carla Fehr suggested to me the value of this strategy.
} 
arguments (2003, pp. 2-5), which suggests that the oppositional view of argumentation is not only limited but also exceptional.

[Argument] situations can often be described well, indeed more accurately [than in terms of opposition], in terms of basic epistemological notions like beliefs, differences in beliefs, hearing and adducing new or different evidence in support of beliefs or their negations, modifying or changing one's beliefs, and so on. With such descriptions "losing" an argument is more accurately portrayed as an epistemological gain: one ends up with beliefs that, in their change or modification, are better supported and more likely to be true. (Rooney, 2003, p. 5)

Thus, a broader epistemological language better captures the range of functions that arguments can have.

Walton considers the employment of argumentative discourse to develop one's own understanding, a purpose that he describes as maieutic, as secondary to the goal of persuasion (1995, p. 103). Walton insists, like Govier, that processes of argumentation require the minimal adversariality of taking up a contrary position, what I have called "oppositionality". Such an oppositional stance is inevitable in the fallacies approach, I have argued, but I am unconvinced by Walton and Govier that it is foundational for argumentation in general, and I suggest that we explore developing the larger context in the epistemological fashion that Rooney identifies.

Argument may not always function with epistemic goals in view, but perhaps it should, because epistemology provides a normative framework for evaluating the multiple purposes that arguments serve. Little epistemological value accrues from quarrels, a type of argument that Walton defines as "dominantly adversarial and non-collaborative" (1995, p. 111). Yet quarreling might be understood as a dysfunctional form of argumentation, aiming to "humiliate and defeat the opponent" (1995, p. 111) and certainly not aiming to develop understanding. Defeat may be part of acceptable argumentation only when directed by the sort of epistemological goals upheld by the Adversary Method.

We need tools to reveal and redress abuses of power differentials in argumentation, and the fallacies approach shows some promise for correcting its own problems. The alternatives to the Adversary Paradigm available in texts from scholars of argumentation and informal logic deserve uptake from liberatory epistemologists. We have the responsibility of ensuring that those texts and the surrounding scholarship play a greater role in philosophy pedagogy and in our own philosophical practice. The dialectical context of fallacy allegation makes it possible to treat mutuality as an ideal of reasoning, and that ideal can be the basis for a more liberatory 
epistemology (Code 1991, pp. 127-281; 1995, p. 142). For instance, Code's concerns with the ad hominem fallacy are significantly addressed by Walton's account of that fallacy (Janack and Adams 1999). So, we might expect the fallacy ad verecundiam (inappropriate appeal to authority) or some other type of fallacy allegation to help address the authoritarian practices that concern feminist epistemologists more generally, and concern me here.

The authoritarian employment of the fallacies approach to argument evaluation that I've revealed may be partly due to respect for the philosophical canon. The canonical version of the fallacies approach is mostly a figment of philosophy textbooks, and the dignity that philosophy commands reflects more than its status as tradition; it mutually reinforces the status of white men in the global North who dominate the tradition. Philosophers might gain a better understanding of the attractions and problems of dignity and the authority it grants our discipline and our textbooks if they were to consider the history and scholarship of the ad verecundiam fallacy. In this way, argumentation theory and informal logic provide one more resource for working responsibly with the authority that philosophers, epistemologists, and epistemology have.

As I have argued elsewhere (Hundleby 2010), the fallacies approach is not static: it varied dramatically through its history, and can continue to respond to changing patterns of reasoning. The plurality of the fallacies approach makes it useful for the practical epistemological concerns of liberatory epistemologists, for situating knowledge in contexts where reasoners have different levels and forms of power. We need tools to reveal and redress in argumentation various abuses of power differentials, and the fallacies approach shows some promise for correcting its own problems and serving as the needed kind of tool. For instance, it might help to identify the errors of reasoning that perpetuate social injustice, such as androcentrism and biological reductionism, and it might help us to confront this reasoning and evaluate its significance (Hundleby, 2010).

Reforming fallacies pedagogy may eliminate one of the last footholds of the Adversary Paradigm in the discipline of philosophy. Admittedly, philosophy is not science, the special sciences were the subject of Kuhn's notion of "paradigm," and for him the demise of a paradigm depends on the ascent of another. Yet, if an epistemological or methodological pluralism is desirable in science, as Helen Longino (1991) maintains, then the same might hold for philosophy.

Updating the fallacies approach to argument evaluation requires better uptake of informal logic and argumentation scholarship, and it needs to be more responsive to the various purposes that argumentation can serve, inside and outside of philosophy. Fortunately, these requirements are complementary: developing a 
fallacies approach with greater attention to contemporary argument situations would encourage greater uptake of developments in argumentation theory.

Acknowledgements: I have many people to thank for asking me a lot of hard questions and directing me toward resources for answering those questions. I especially thank Bob Pinto for his generous coaching without which I might never have completed this paper. I also thank an audience at the University of Windsor's Centre for Research in Reasoning, Argumentation, and Rhetoric (CRRAR), particularly Ralph Johnson for his detailed comments, and Tony Blair for pressing me to analyze the textbooks. Any remaining errors or oversights are purely my fault. Thanks to Phyllis Rooney for her patience and ongoing consultation as the paper took shape, to Kate Parr for regular discussions about argumentation pedagogy, and to Margaret Hundleby for her editorial advice. Further discussion of this paper came from Melinda Munro, Jeff Noonan, a meeting of the North American Society for Social Philosophy, and a meeting of the Canadian Society for Women in Philosophy. The University of Windsor Outstanding Scholar's Program provided financial support for Dina D'Andrea's assistance with the research.

\section{References}

Alcoff, L.M. (1993). How is epistemology political? In R.S. Gottlieb, Ed., Radical philosophy: Tradition, counter-tradition, politics. Temple University Press.

Bassham, G., Irwin, W., Nardone, H., and Wallace, J.M. (2005). Critical thinking: A student's introduction. Toronto: McGrawHill.

Bickenbach, J.E. and Davies, J.M. (1997). Good reasons for better arguments: As introduction to the skills and values of critical thinking. Orchard Park, NY: Broadview.

Blair, J.A. (2004). Argument and its uses. Informal Logic 24(2), 137-151.

Blair, J.A. (1995). The place of teaching fallacies in teaching reasoning skills or critical thinking, in Hans V. Hansen and Robert Pinto (Eds.), Fallacies: Classic and contemporary readings. University Park, PA: Penn State Press.

Boss, J.A. (2010) Think: Critical thinking and logic skills for everyday life. New York: McGraw-Hill.

Carey, S.S. (2000). The uses and abuses of argument: Critical thinking and the fallacies. Mountain View, CA: Mayfield.

Code, L.B. (1995). Rhetorical spaces: Essays on gendered locations. New York: Routledge. 
Code, L.B. (1991). What can she know? Feminist theory and the construction of knowledge. Ithaca: Cornell University Press.

Cohen, D.H. (1995). Argument is war... and war is hell: Philosophy, education, and metaphors for argumentation. Informal logic 17(2), 177-88.

Copi, I.M., and Cohen, C. (2005). Introduction to logic, $12^{\text {th }}$ edition. Upper Saddle River, NJ: Prentice Hall.

Copi, I.M., Cohen, C., and Flage, D.E. (2007). Essentials of logic, $2^{\text {nd }}$ edition. Upper Saddle River, NJ: Pearson.

Crouch, M. (1991). Feminist philosophy and the genetic fallacy. Hypatia: A journal of feminist philosophy 6(2), 104-117.

Damer, T.E. (2005). Attacking faulty reasoning: A practical guide to fallacy-free arguments, sixth edition. Belmont, CA: Wadsworth.

Eemeren, F.H. van, Grootendorst, R., Snoeck Henkemans, F., et al. (1996). Fundamentals of argumentation theory: A handbook of historical backgrounds and contemporary developments, Mahwah, NJ: Lawrence Erlbaum Associates

Engel, S.M. (2000). With good reason: An introduction to informal fallacies, $6^{\text {th }}$ edition. Boston: St. Martin's Press.

Epstein, R.L. (2002). Critical thinking. Belmont, CA: Wadsworth.

Flage, D.E. (2004). The art of questioning: An introduction to critical thinking. Upper Saddle River, NJ: Pearson.

Glenn, C. (2004). Unspoken: A rhetoric of silence. Carbondale, IL: University of Illinois Press.

Goodwin, J. (2007). Argument has no function. Informal logic 27 (1), 69-90.

Goodwin, J. (1998). Forms of authority and the real ad verecundiam, Argumentation 12, 267-280.

Govier, T. (2010). A practical study of argument. Belmont, CA: Wadsworth.

Govier, T. (1999). The philosophy of argument. Newport News, Virginia: Vale Press.

Gula, R.J. (2002). Nonsense: A handbook of logical fallacies. Mount Jackson, VA: Axios Press.

Hanrahan, R. and Antony, L. (2005). Because I said so: Toward a feminist theory of authority. Hypatia: A journal of feminist philosophy 20(4), 59-79.

Hansen, H.V. (2006). Whately on arguments involving authority. Informal logic 26(3), 319-40.

Harding, S. (1991). Whose science? Whose knowledge? Thinking from women's lives. New York: Routledge.

Harding, S. (1986). The science question in feminism. Ithaca: Cornell University Press.

Hartsock, N.C.M. (1983). The feminist standpoint: Developing the ground for a specifically feminist historical materialism. in $\mathrm{S}$. 
Harding and M.B. Hintikka (Eds.), Discovering reality. Boston: D. Reidel.

Hitchcock, D. (1995). Do fallacies have a place in the teaching of reasoning skills or critical thinking?, in H.V. Hansen and R. Pinto (Eds.), Fallacies: Classic and contemporary readings, University Park: Penn State Press.

Hughes, W. and Lavery, J. (2008). Critical thinking: An introduction to the basic skills, $5^{\text {th }}$ edition. Peterborough, Ontario: Broadview.

Hundleby, C. (2010). Fallacy forward: situating and revising fallacy theory. Proceedings of OSSA 9: Argument cultures. (CD) Centre for Research in Reasoning, Argumentation and Rhetoric, University of Windsor.

Hundleby, C. (1997). Where Standpoint Stands Now. Women \& politics $18(2)$.

Inch, E.S. and Warnick, B. (2002). Critical thinking and communication, $4^{\text {th }}$ edition. Toronto: Allyn and Bacon.

Janack, M. and Adams, J. (1999). Feminist epistemologies, rhetorical traditions and the ad hominem, in Sutherland, C.M., and Sutcliffe, R., (Eds.) The changing tradition: Women in the history of rhetoric. Calgary: University of Calgary Press.

Johnson, R.H. (1987). The blaze of her splendours. Argumentation 1: 239-253.

Johnson, R.H. and Blair, J.A. (2006). Logical self-defense. New York: International debate education association.

Kenyon, T. (2008). Clear thinking in a blurry world. Toronto: Nelson.

Kuhn, T. (1996). The structure of scientific revolutions, third edition. Chicago: University of Chicago Press.

Leblanc, J. (1998). Thinking clearly: A guide to critical reasoning. W.W. Norton \& Co.

Lee, Stephen P. (2002). What is the argument? Critical thinking in the real world. New York: McGraw-Hill.

Longino, H. (1991). Science as social knowledge. Princeton: Princeton University Press.

Mackenzie, J. (1988). Authority. Journal of philosophy of education 22(1), 57-65.

Moore, B.N. and Parker, R. (2007). Critical thinking, $8^{\text {th }}$ edition. New York: McGraw-Hill.

Moulton, J. (1983). A paradigm of philosophy: The Adversary Method, in S. Harding and M.B. Hintikka (Eds.), Discovering reality. Boston: D. Reidel.

O'Keefe, D. (1977). "Two concepts of argument." Journal of the American Forensic Association, 13, 121-28.

Porter, B.F. (2002). Fundamentals of critical thinking. New York: Oxford University Press. 
Romain, D. (1997). Thinking things through: Critical thinking for decisions you can live with. Mountain View, CA: Mayfield.

Rooney, P. (2004). Feminism and argumentation: A response to Govier. Presented at the 2003 Ontario Society for the Study of Argumentation Conference, Informal Logic at 25. Available at:

http://web2.uwindsor.ca/faculty/arts/philosophy/ILat25/edited rooney.doc

Rudinow, J., Barry, V.E., Letteri, M. (2008). Invitation to critical thinking, $1^{\text {st }}$ Canadian edition. Toronto: Thomson.

Saindon, J. (2008). Argument and argumentation. Toronto: Nelson.

Schwarze, S. and Lape, H. (2000). Thinking Socratically. Prentice Hall.

Schick, T., Jr. and Vaughn, L. (2005). How to think about weird things, $4^{\text {th }}$ edition. New York: McGraw-Hill.

Sinclair, L. and Kunda, Z. (2000). Motivated Stereotyping of Women: She's Fine if She Praised Me but Incompetent if She Criticized Me, Personality and social psychology bulletin, 25(11): 1329-1342.

Teays, W. (2006). Second thoughts: Critical thinking for a diverse society, $3^{\text {rd }}$ edition. New York: McGraw-Hill.

Tindale, C. (2007a). On fallacy, in H.V. Hansen and R.C. Pinto, (Eds.) Reason reclaimed: Essays in honour of J. Anthony Blair and Ralph H. Johnson. Newport News, VA: Vale Press.

Tindale, Christopher. (2007b). Fallacies and argument appraisal. New York, NY: Cambridge University Press: 155-170.

Thomson, Judith Jarvis. (1971). A defense of abortion, Philosophy and public affairs, 1(1).

Vaughn, L. and MacDonald, C. (2008). The power of critical thinking, Canadian edition. Don Mills, Ontario: Oxford University Press.

Walton, D. (2006a). Argumentation schemes for presumptive reasoning. Mahway, NH: Lawrence Ehrlbaum Associates.

Walton, D. (2006b). Fundamentals of critical argumentation. New York: Cambridge University Press.

Walton, D. (1997). Appeal to expert opinion: Arguments from authority. University Park, PA: The Pennsylvania State University Press.

Walton, D. (1995). A pragmatic theory of fallacy. Tuscaloosa: Alabama University Press.

Wilson, D.C. (1999). A guide to good reasoning. New York: McGraw-Hill.

Woods, J. (2004). The death of argument: Fallacies in agent based reasoning. Boston: Kluwer.

Woods, J., Irvine, A. and Walton, D. (2004). Argument: Critical thinking, logic and the fallacies, second edition. Toronto: Prentice Hall. 